\title{
ATTITUDES AND BEHAVIOR OF THE PRODUCTS OFFERED IN A TOURIST UNIT
}

\author{
Popa Eugen Andrei ${ }^{9}$ \\ Foris Diana $^{10}$
}

\begin{abstract}
The present study consists of identifying certain types of behavior, reactions and preferences of consumers and pastry products of a tourist unit, which are part of the traditional local gastronomy. The main objective of the study is to identify the preferences of foreign tourists regarding traditional pastry and confectionery products in order to improve the quality in the production sector. In order to achieve the objective, the "shadow" observation was used as a research method for a period of two months. The sample consisted of twenty foreign tourists who were interested in buying traditional pastry and confectionery products. During the observation, several aspects were analyzed, such as: the type of consumer behavior, the reactions and verbal expressions regarding the quality of the products, etc. The results obtained by the observation method confirmed the preference especially for the pastry products, as compared to the confectionery products. The conclusions of the study highlight the importance of observing foreign clients, which led to the proposal of several measures to improve the services of the tourist unit, but also to a better tourist image of the unit in the area of the tourist resort Bran. Jud. Brasov.
\end{abstract}

Key words: traditional gastronomy, observation, pastry and confectionery

\section{INTRODUCTION}

Tourism is a very important industry for the future, both globally and regionally, locally or nationally. Tourism, as a phenomenon and as an activity is unique in its own way by its dependence on the environment, the social and cultural environment, on their values, while ensuring sustainability. Therefore, a commercialized tourist product must be carefully designed so that it does not affect the environment and the smooth conduct of the tourist activities. Also, the development of the tourism products at a competitive level leads to the improvement of the quality of life and the relaunch of the disadvantaged areas. The success of a business idea is determined by the way the consumer perceives the quality offered by the provider.

If the service offered is of a very good quality, the consumer will return to the respective tourist unit a second time, because he was satisfied with the services offered by the service provider. (Tomescu, 2014).

\footnotetext{
${ }^{9}$ Eng.Student master, Transilvania University of Brasov, Faculty of Food and Tourism, The boulevard of heroes 29, Brașov, România

${ }^{10}$ Assoc. Prof. Dr., Transilvania University of Brasov, Faculty of Food and Tourism, The boulevard of heroes 9, Brașov, România
} 
Tourism is a very important economic sector that leads to a significant contribution to local, regional and national development, an example being the tourist area RucărBran where the number of foreign tourists has increased from year to year. In this case, a very visited tourist objective is Bran Castle, which became very well known due to the association with the legend of Count Dracula, built in the 14th century by the merchants from Brasov on the place of a former fortification of the Teutonic knights, in a key location from a strategic point fo view, on an old commercial transcarpathian road. The story behind the walls of the castle says that the wife of a prince fighting the Turks killed herself, being convinced that her husband died in battle. Angered by the deity, the prince makes a pact with the devil and becomes an immortal vampire, who will forever look for women alike his wife who killed herself. The legend is inspired by the historical figure of the Moldavian ruler Vlad nicknamed Țepeș because he executed his enemies by impalement. The historical truth is that Vlad Țepeș was just passing through Bran Castle, the edifice being currently a museum visited by millions of tourists. (Ministry of Tourism, 2017). Thus, the RucărBran tourist area has developed considerably from a touristic point of view, subsequently numerous places that offer accommodation and food services appeared, and also entertainment services respecting the local tradition and culture. BranMoieciu Tourist Resort presents an impressive tourist potential, being an important component for the touristic offer in this region. Due to this fact, a considerable number of tourists arrive at this tourist resort in Transylvania to spend their holiday. (POSDRU, 2012).

The study tries to provide information and identify important elements for identifying certain types of behavior, reactions and consumer preferences regarding products that capitalize on local traditional gastronomy and are marketed in tourist food establishments, located in rural tourism destinations.

\section{Traditional products in the consumers' preferences in tourist establishments}

Currently, those traveling a lot are very experienced in doing this, carefully planning their tourist destinations. There are those who want to escape their daily routine in a world of freedom and novelty. Therefore, the discovery of the production sector within a tourist food unit is a very important aspect in the quality of the holiday experience for foreign tourists. (UNWTO, 2012).

According to the good practice guide issued by the Ministry of Agriculture and Sustainable Development in 2014, the traditional product is a food product obtained in the national territory where local raw materials are used, which does not have in its composition food additives, based on a traditional recipe, a mode of production or processing, including a traditional technological process and which is distinguished from other similar products. A traditional or organic product has, besides the price, a 
value of its own. These products come from a production system that does not harm the environment, does not pollute water or soil and does not disturb the biodiversity of the production areas. In the case of these traditional products, we talk about the continuity of customs and varieties of seeds that ensure at national level, a whole food and cultural diversity (Ministry of Agriculture and Sustainable Development, 2015). Consumers usually make certain confusions between different product categories, such as traditional products, organic products and local products. However, the traditional products have become highly appreciated for the originality and the quality of the taste they have, the demand for their purchase is increasing from year to year. (Chiciudean, 2014).

The culinary culture was influenced by the structural changes that were made in our society. Phenomena such as globalization, urbanization, modernization and migration have transformed the way modern civilization consumes food. (UNWTO, 2017). The consumption of food and beverages is directly influenced by certain factors such as taste, medical care, cost, satisfaction and convenience, all of which generate a pattern of behavior and a certain manifestation of human identity. (Privitera, D., Nedelcu, A., $\&$ Nicula, V., 2018). When new tourist destinations are visited, this pattern of tourists' behavior changes because food is an essential part of any travel experience. (Scott \& Duncan, 2017).

Many researchers consider gastronomic tourism to be a key tourist activity that involves a number of experiences for the general public, such as cooking courses or food festivals. Food is viewed as a supportive experience in tourism, as Yeoman (2012) states, which states that food refers to new tastes, new knowledge and concepts as a symbol in the economy of experience.

Discovering a tourist destination through its cuisine is not only an interesting and satisfying experience, but also a provocative way for visitors to this phenomenon of globalization. This fact suggests that the way to travel for gastronomic reasons, to enter the culture of the place in a complex way is a very well-founded argument. Moreover, the gastronomic experiences can give value to any type of tourist activity in a pleasant way for a wide range of potential consumers.

Thus the need arises to study the gastronomic experience, in order to find out what the preferences of the consumers from other countries regarding the Romanian pastry and confectionery products. About consumer behavior we can say that it involves certain decisions, activities, ideas or experiences that ultimately satisfy their needs and desires. (Cohen, S. A., 2014). People have always liked sweets, children being the ones who generally prefer sweet taste instead of salty or bitter. (Allen, T., 2010). We can say that sweets can not miss from the menu of those who like to eat well, these are, in reality, the highlight of a rich meal. Although it is the last meal brought to the 
table, the dessert is the first we will remember later. (Iordan, V., 2011). Due to the multitude of gourmet confectionery and pastry products that have appeared and continue to appear on the market, it is important to know what are the factors that motivate or influence consumers to purchase these products. The established objective was to identify the preferences of consumers from other countries, through their attitudes and decision to purchase a gastronomic product. The research hypotheses refer to the identification of the way in which the knowledge of the foreign consumer about a particular product positively or negatively influences his/her purchase in a tourist unit with gastronomic functions. At the same time, it was followed the influence of the attitude of the sales personnel in its relation with the buyer, regarding a product, intervening on the decision to purchase the consumer.

\section{METHODOLOGY}

Given the research problem, namely, the identification of the preferences of foreign tourists, through attitudes and the decision to purchase Romanian gastronomic products, the qualitative type research was used, applying as a research method the simple observation at the point of sale as well as the observation of the consumer behavior. The aim of the study is to improve the quality of services in the production sector and the sales office of a tourist unit with public catering functions, located in a tourist resort.

The tourist unit chosen for this research study was the Panner Confectionery located in the Bran tourist resort, located in the rural area, in Braşov county, Romania. This is a tourist structure with very attractive gastronomy functions and it is easy to access by local consumers as well as by tourists. The very large number of tourists who walk inside the tourist unit is due both to the specific architecture but also due to its placement, near the most popular and famous tourist objective in Transylvania, namely Bran Castle - a medieval castle that owes its name and its huge tourist attraction to the Count Dracula, the character of Bram Stoker's novel, the castle that houses the Bran Museum, where collections of ceramics, furniture, weapons and armor are on display, and, in the castle's courtyard, there is a small village museum with traditional houses from the Rucăr-Bran corridor region. The architecture of the food unit recreates the local specificity in a modern interpretation. The strong stone foundation, the reinterpreted porch, as an element of connection between interior and exterior, the simple form of the building and the interior finished with reclaimed wood, all recall certain elements from the archaic period of the Bran area. At the same time, the complete transparency towards the street, the proportions of the building, and the dry treatment of the details, place the construction in the modern period. Also, the counter system on which the eaves rests enriches the simple composition of the facade, being a structure and an ornament at the same time. From the outside, its 
image is clear, clean, a sign easy to notice, being an important attraction in the area. Inside, it is found a simple, welcoming ambience, without many decorative elements so that the emphasis is placed on the presented products. (https://xn--urlaub-inrumnien-2qb.de/ro/uir/de-visited-location-visited -bran castle/)

Starting from the analysis of the specialized literature and taking into account the research issues, the basic aspects, the questions of the researcher as well as the main objectives to be followed in carrying out the study were formulated, to be found in Tab no.1. The main objectives refer to the way of observing the attitudes and behaviors of foreign consumers within a tourist unit, in this case a confectionery.

Tab. 1. The main objectives of qualitative research

\begin{tabular}{|c|c|c|}
\hline Basic aspects & Researcher's questions & Objectives \\
$\begin{array}{c}\text { Consumers' attitude } \\
\text { towards the design of } \\
\text { the tourist unit }\end{array}$ & $\begin{array}{c}\text { consumer's attitude } \\
\text { towards the cake } \\
\text { shop's design? }\end{array}$ & $\begin{array}{c}\text { O1. Measuring the } \\
\text { attitude of consumers } \\
\text { towards the cake shop's } \\
\text { design. }\end{array}$ \\
\hline $\begin{array}{c}\text { Identification of the } \\
\text { consumer's attitude and } \\
\text { behavior in contact } \\
\text { with the finished } \\
\text { products from a tourist } \\
\text { unit }\end{array}$ & $\begin{array}{c}\text { 2. How is the consumer's } \\
\text { attitude and behavior in } \\
\text { contact with the finished } \\
\text { products of a tourist } \\
\text { unit? }\end{array}$ & $\begin{array}{c}\text { O2. Identification of } \\
\text { the consumer's attitude } \\
\text { and behavior regarding } \\
\text { the finished products of } \\
\text { a tourist unit }\end{array}$ \\
\hline $\begin{array}{c}\text { The degree of } \\
\text { consumer preference } \\
\text { regarding a greater } \\
\text { diversity of products } \\
\text { within a tourist unit }\end{array}$ & $\begin{array}{c}\text { 3. What is the degree of } \\
\text { preference of consumers } \\
\text { from a greater diversity } \\
\text { of products in a tourist } \\
\text { unit? }\end{array}$ & $\begin{array}{c}\text { O3. The degree of } \\
\text { preference identified } \\
\text { within a tourist unit, } \\
\text { compared to the } \\
\text { finished products }\end{array}$ \\
\hline
\end{tabular}

To achieve the objectives, a two-month observation period (April-May 2019) was used as a research method. The sample consisted of twenty foreign tourists who were interested in buying traditional pastry and confectionery products. During the study, several aspects were analyzed, such as: the type of consumer behavior, the reactions and verbal expressions regarding the quality of the products, and so on. 
The time allocated to the study, over the course of the 2 months, was divided into two stages, namely: the first observation interval was between 10:00-13:00 and the second interval was performed between 16:00-19:00. The consumer observation was made on Tuesdays, Thursdays, Fridays and Saturdays, with some differences between them regarding the flow of customers of the tourist unit.

\section{RESEARCH RESULTS}

Applying the observation method behind the point of sale of the tourist unit, it was found that, of the twenty foreign consumers in the sample, thirteen were pleased to purchase products from the range of pastry sector, while the remaining seven consumers they were more than happy to buy products from the range of confections in the confectionery sector. The choice of products from a variety of product assortments within a tourist food unit, in this case from a confectionery, is very interesting to analyze, because, behind the decision to purchase a product, there are more factors that ultimately led to the choice of the respective products.

Thus, everything started from the outside, from the moment the consumer came into contact with the overall view of the unit but also of the natural environment in its surroundings. It was noted his reaction to the location, with what he visually observes, his delight to enter an unknown unit and to share this experience with those around him. While he entered the cake shop, the expressive mimicry of the face was observed, his attitude in contact with the seller of the location and the choice of a product or more in the range of assortments offered for sale. Each of these foreign consumers were impressed by the unit's design, the simplicity of the furniture and decoration, but, at the same time, very accessible and easy to use. Impressive were also the kindness offered by the seller and her warmth and smile, factors that led to finding out more information about the story of the unit, but also the details of the products that were made available to customers to purchase. First of all, each of us visually sees everything around us, so those consumers who once observed the products in the sales showcase, were impressed by the diversity of the colors of the products, their freshness, their proportion, their curiosity of how they taste. Secondly, after those customers have hardly decided on a product or two, they sit at a table inside the unit, starting to taste, after they have smelled and analyzed the texture of the product. Regarding the tasting of a finished product, if we want to enjoy that product, we must become aware of the experience. Thus, the foreign tourists within the sample knew how to use their senses and enjoy the product in close relation with the atmosphere created inside the location. Many of these consumers have also chosen to buy products to-go, buying more products to find out their taste later.

In order to present the relevant information in a structured way, the obtained results are grouped based on the main objectives of the research. 


\section{O.1: MEASURING THE ATTITUDE OF CONSUMERS TOWARDS THE CAKE SHOP'S DESIGN}

From the outside of the tourist unit, the foreign consumer is first and foremost fascinated by the architectural aspect of the unit, making him want even more to discover the inside of the shop, to find out the story and the way that led to its creation. In this case, the confectionery where the study was carried out has succeeded numerous times in attracting the customers due to the design that combines the traditional and the modern and that respects, at the same time, the culture and the specificity of the place. The point of sale and the production center are on the ground floor, customers often asking if at the second level there are accommodation places or the possibility to serve meals. Overall, foreign consumers were delighted by the location itself and the services offered by the staff, leaving the shop with a very good impression of this place.

\section{O.2: IDENTIFICATION OF THE CONSUMER'S ATTITUDE AND BEHAVIOR REGARDING THE FINISHED PRODUCTS OF A TOURIST UNIT}

Once the client came into contact with the finished products presented at the point of sale within the tourist unit with gastronomy functions, the client needed some time to decide on one or more products, because the variety of product assortments, their colors and how they are presented are complex decision-makers for a foreign consumer. The exchange of information between the customer and the sales staff was related to the way of processing the products, the ingredients contained, and so on. Many times the customers have also come into contact with the staff in the production laboratory, their joy and satisfaction being more evident after obtaining detailed information related to the production technology of the products. For the foreign consumers, the disponibility of receiving any information related to the location and the presented products, but also the attention and kindness given by the designated personnel within the tourist unit, mattered a lot. A sincere smile offered by the staff to the consumer fully guarantees the satisfaction of his wishes and needs.

\section{O3. THE DEGREE OF PREFERENCE IDENTIFIED WITHIN A TOURIST UNIT, COMPARED TO THE FINISHED PRODUCTS}

It is often difficult for consumers to choose from a variety of product assortments, where their colors and proportions vary. To get to choose a product, the consumer needs time to think, to analyze each product separately, to obtain information about it, its effects on the human body. Also, here intervine the preference of each consumer, the preference to sweet or salty, the part of innovation and creativity found in 
confectionery products or the simpler, more traditional part of the pastry side. All the finished products presented in this tourist unit, of confectionery-pastry type are based on traditional recipes that respect the traditions and customs of the Bran-Moieciu tourist area, using traditional local ingredients. Because of this, tourists were very pleased and satisfied when they discovered the taste of each product they chose for tasting and purchase.

\section{CONCLUSIONS}

Following the study in which it was applied as a research method, observing on a certain typology of consumers, it was found a consumer's preference especially for pastry products. The availability of the staff and the exchange of information between foreign tourists and the sales staff matters, this being able to lead to an improvement of the image of the gastronomy tourism unit, as well as to an increase in the consumers' demand for more products. The observation of the behavior of foreign tourists reveals that they greatly appreciated the attention paid by the sales staff, the kindness and patience given during the contact period with them and that they were influenced in purchasing products due to the quick access to the information about the product and the place, as well as the fact that all the finished products presented in the tourist unit where the study was carried out, are based on traditional recipes that respect the traditions and customs and use local ingredients. At the same time, the consumers were very open to new, to explore new places and to interact and socialize with the local people.

The results of the study present useful and practical implications for the public food units, and especially those from tourist resorts located in rural areas, emphasizing the importance of using traditional recepies and of the appropriate behavior of the staff in relation with the consumers. At the same time, the present study also has theoretical implications for the researchers in the field, being able to contribute to the consolidation of the existing researches and to offer new directions of approach for future research, by developing quantitative researches regarding the attitudes and behavior of foreign tourists regarding the gastronomic products that capitalize on traditional recipes and use local ingredients, and correlations regarding the architectural aspect and the offered services. 


\section{REFERENCES}

1. Allen, T., Bastable, J., Binnery, R., Harwood, J., Healey, T., \& Mason, A., (2010). Where did everything start from? Why is our world the way it is? (De unde a pornit totul? De ce lumea noastră este aşa cum este?)

2. Cohen, S., A., Prayag, G., \& Moital, M. (2014). Consumer behavior in tourism: Concepts, influences and opportunities, Current Issues in Tourism, 17, 872-909.

3. Chiciudean, I.D. (2014). Local products and consumers' perception of them. Retrieved from http://www.usamvcluj.ro/files/teze/2014/chiciudean.pdf

4. Ferrin, P.F., Turrientes, A.C., Bande, B., Minon, M.A., \& Ladero, M.G., (2018). The valuation and purchase of food products that combine local, regional and traditional features: The influence of consumer ethnocentrism, Food Quality and Preferences, 64, March 2018, 138-147.

5. Iordan, V. (2011). Sweets-recipes full of flavor for dream desserts,Editura Adevarul Holding, Buchurest.

6. Gheorghe, G., Tudorache, P., \& Nistoreanu, P. (2014). Gastronomic Tourism, A new trend for Contemporary Tourism?, Cactus Tourism Journal, 9(1), 12 21.

7. Ministry of Agriculture and Sustainable Development, (2015). Traditional foods. Thematic publication no. 38, Year II. Retrieved from http://madr.ro/docs/rural-development/rndr/thematic-bulletins/PT38.pdf

8. Ministry of Tourism, (2017). Romania-Explore the Carpathian Garden.

9. POSDRU, (2012). Entrepreneurs in Tourism-Pensions in Romania. Qualitative study with Romanian tourists. Southern Mountain Region. Retrieved from http://www.intreprinzatorturism.ro/wpcontent/uploads/2012/05/ITPR-Studiu-calitativ-turisti-romani-Regiunea-SudMuntenia_martie-2012.pdf

10. Privitera, D., Nedelcu, A., \& Nicula,V. (2018). Gastronomic and Food Tourism As An Economical Local Resource: Case Studies from Romania and Italy. GeoJournal of Tourism and Geosites, 21(1), 143-157

11. Tomescu, I., E. (2014). Total Quality Management in the tourist activity, 3, 76-82

12. UNWTO, (2017). Affiliate Members Report, Volume sixteen, Second Global Report on Gastronomy Tourism, UNWTO, Madrid. Retrieved from http://cf.cdn.unwto.org/sites/all/files/pdf/gastronomy report web.pdf

13. UNWTO, (2012). Global report on Food Torism. Madrid: World Tourism Organization. from http://cf.cdn.unwto.org/sites/all/files/pdf/global_report_on_food_tourism.pdf

14. https://xn--urlaub-in-rumnien-2qb.de/ro/uir/de-visited-location-visited -bran castle/ 